\title{
Preauricular full-thickness skin grafting in medial canthal reconstruction
}

\section{Rafael Corredor-Osorio}

\author{
Corredor Ocular Center of Specialized Ophthalmology. Av. Bolivar, CC Las Acacias, local 31, Valera (Trujillo), Venezuela
}

Corresponding author: Rafael Corredor-Osorio, MD., E-mail: raficorredor@yahoo.com

\begin{abstract}
Basal cell carcinoma in medial canthal is a surgical challenge to oculoplastic surgeon. We report a case an 80 -year-old woman who presented with a vegetative tumor in the right inferior medial canthus that increased slowly in size over the past two years. An excisional biopsy from the tumor was suggestive of a basal cell carcinoma. A full-thickness excision of the tumor within the oncologic safety limits, was performed. A wide range of reconstruction techniques should be customized to the individual patient. In this case, the use of a preauricular full. Thickness skin graft was a favorable option, without complications, and with acceptable functional and cosmetic results. The aim of the treatment is to restore anatomy, functional and cosmetic of the patients.
\end{abstract}

Key words: Basalcellcarcinoma; Medial canthal region; Full-thickness skin graft; Eyelid reconstruction

\section{INTRODUCTION}

Periocular skin tumors are the most common tumour encountered in ophthalmic practice. Basal cell carcinoma (BCC) is the most common malignant eyelid tumour; it has a low risk for metastasis but considerable invasive potential [1]. BCC of periocular area are localized in the inferior eyelid, medial canthus and superior eyelid [2]. Complete surgical excision remains the "gold" standard of treatment it produces excellent results if the tumour is completely removed [1]. Reconstruction of the medial canthal defect created after removal of tumour is the challenge to the oculoplastic surgeon.

Reconstructive techniques can be classified considering the anatomical area requiring treatment: superior eyelid, inferior eyelid, and inner or external canthus [3]. Simplifying, we can distinguish: direct wound closure, "laisser faire", free skin grafts, and different types of skin flaps $[3,4]$. Direct closure is reserved to very small defects, 'laisser faire' can lead to a remarkable extent of undesired scarring and a cosmetically unfavorable outcome. Free skin grafts require a healthy, wellperfused transplant bed. In case of very deep defects, especially if the defects reach the surface of the bone, free skin grafts are unsuitable. The risk of graft necrosis is high in these situations, and furthermore grafts of the thin skin, for example from the upper eyelids, can lead to a remarkable retraction of the reconstructed region. Finally the risk of hypertrophy of the free skin transplant is highest when transferred into the medial canthus. For these reasons, is that free skin grafts might be even used too often [3]. By definition, a skin flap differs from a skin graft because it consists not only of skin but also of subcutaneous tissue with its subdermal plexus of vessels. Although it is completely raised from the underlying tissue, it is still connected by at least one side to the surrounding skin and fat. It is because of the vessels contained in this pedicle that the flap can preserve its own blood supply, independent of the site on which it is placed [4].

Full thickness skin grafts (FTSG) are composed of epidermis and the entire dermis [5,6].Full-thickness eyelid defects often lead to conjunctival irritation, keratopathy, conjunctival inflammation, corneal ulceration, and even blindness [7]. FTSG are nowfrequently used by plastic surgeons as anterior lamellasubstitutes in eyelid reconstruction surgery, 
providing tissuewith similar color, texture, and thickness. The perioculararea is considered a suitable host, having a rich vascularsupply for capillary regrowth, as well as collagen producingfibroblasts which help in graft adherence $[1,2]$. This successfulcombination of graft and host has subsequently made itwidely used in eyelid reconstruction surgery after trauma, burns, and tumour removal [6]. The aim of the present report was to present the reconstructive techniquein inferior medial canthus with preauricular full-thicknessskin and here we showed the illustration of the respective technique.

\section{CASE REPORT}

An 80 year-old woman presented to us a complaint of an asymptomatic tumor located in the right inferior medial canthus for two years. The lesion is $1.1 \mathrm{~cm}$ x $0.9 \mathrm{~cm}$ in size, with central ulceration, was insidious onset increased in size (Fig. 1). Excisional biopsy of the lesion was suggestive of basal cell carcinoma. In this type of tumor and full-thickness excision is important.

\section{OPERATIVE PROCEDURE}

The procedure is performed under local anesthesia with intravenous sedation and magnification. Surgical excision margins were traced from the lesion border, with a margin of normal skin of $5 \mathrm{~mm}$ with a marking pencil, before the subcutaneous injection of $50 \%$ bupivacaine $0.5 \%$ and $50 \%$ lignocaine $2 \%$ with epinephrine (concentration, 1 in 200.000). A \# 15 Bard-Parker blade is used to inside the tumor. A fullthickness is carried gradually deeper until all tumor is excised, with a margin of normal skin of a least $5 \mathrm{~mm}$. Bleeding is stopped completely prior to graft placement. (Fig. 2). A template of the defect and a marking pen is used to make an outline around the template. The template is placed over preauricular area and traced with marking pen (Fig. 3a). The graft is 20 percent larger than the defect, to allow contracture of the graft. The site is injected subcutaneously with $50 \%$ bupivacaine $0.5 \%$ and $50 \%$ lignocaine $2 \%$ with epinephrine (concentration, 1 in 200.000) to supply hemostasis and hydrodynamically facilitate the dissection.

Next, we began harvesting the right preauricular full-thickness skin graft by making skin incisions using a \#15 Bard-Parker blade. We then proceeded with dissection immediately in a subdermal plane

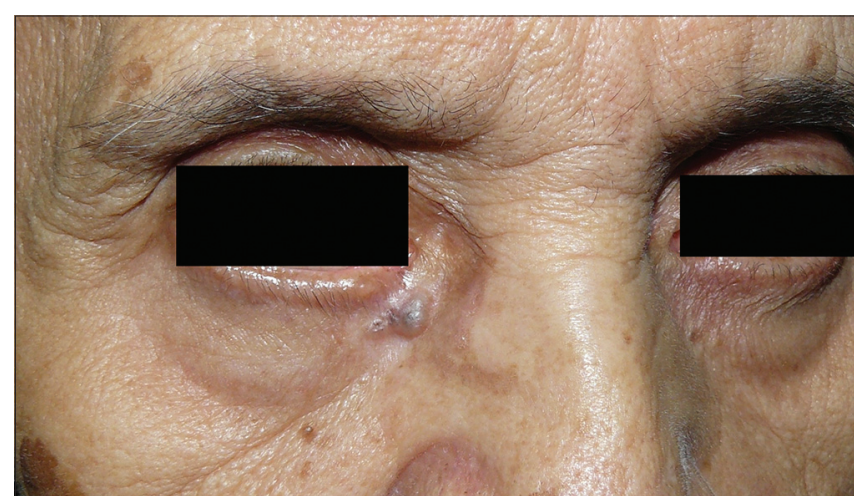

Figure 1: Preoperative Basal cell carcinoma of the medial canthal region.

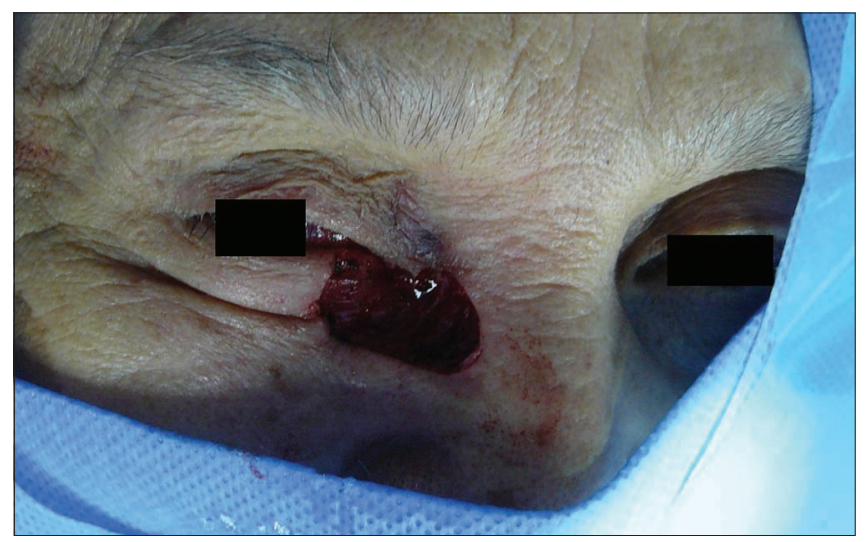

Figure 2: The bleeding points were cauterized. Meticulous hemostasis is achieved prior to graft.

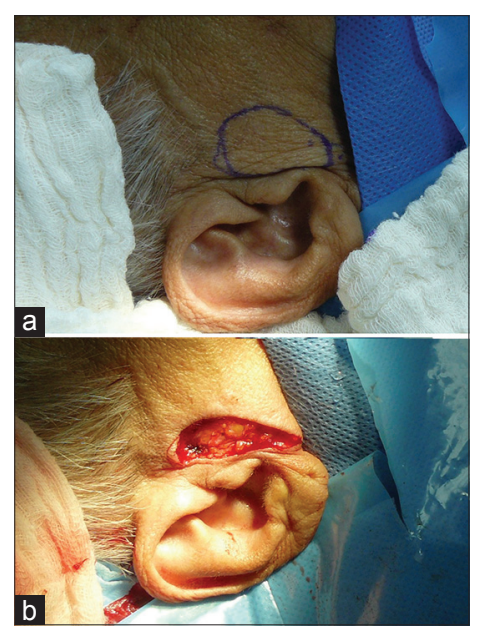

Figure 3: (a) Preparation of a preauricular full-thickness skin graft, (b) Preauricular full thickness skin donor area.

with minimal fat along the skin graft. The thin fullthickness skin graft was removed and its base resected with Westcott scissors (Fig. 3b). We then draped over the surgeon's glovedfinger a dermis up, and all subcutaneous fatty tissue is trimmed away. The graft is transferred andsutured into recipient site con 6/0 nylon sutures. Every third suture is long left (Figs. 4a and 4b). 
Stab incisions are made in the graft to allow blood to drain. A thin layer of antibiotic ointmentis placed over graftand other layer antibiotic ointment-impregnated gauze, is applied tightly over graft with the long sutures tied over it. The traction suture is fixed to the brow. Ointment is used to coat the bolster and two compressive eye pads are applied to eyelid. The area preauricular is closed with 6-0 nylon sutures.

The dressing, bolster, and traction are removed in 4 days. The skin sutures are removed in 10 days (Fig. 5). The final histopathology confirmed the tumor asa nodular basal cell carcinoma with tumor-free margins

\section{DISCUSSION}

Skin grafting is the oldest form of tissue reconstruction known. Texts documenting the use of skin grafts for soft tissue reconstruction date back 2500 years. The first known description was found in India, in which a skin graft was used to reconstruct an amputated nose.

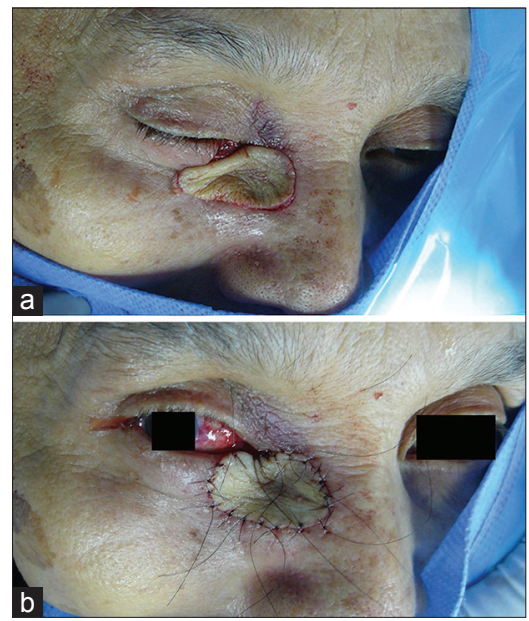

Figure 4: (a) Full thickness skin graft inset onto inferomedial canthus, (b) Appearance of defect after reconstruction with ipsilateral preauricular skin graft.

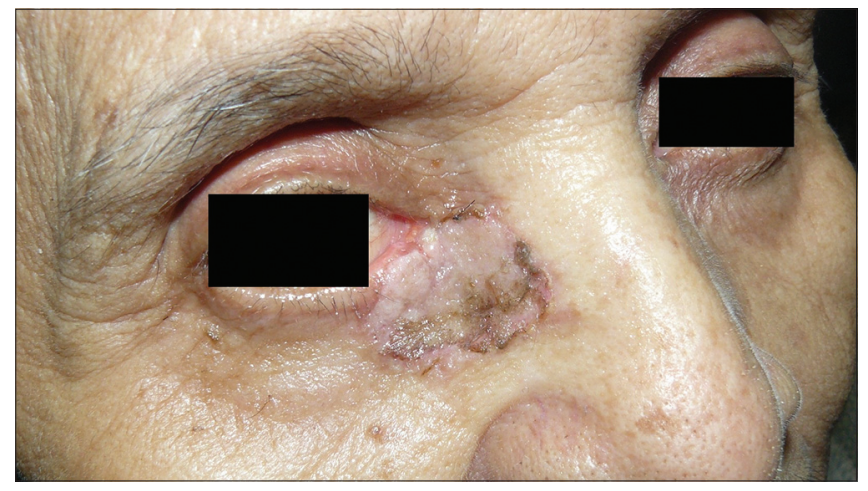

Figure 5: Two weeks follow-up results.
Modernization of the technique started to come about in the $19^{\text {th }}$ century, with descriptions of the pinch graft in 1869 and the FTSG in 1875 [8].

The main advantages of FTSG areaviability, low metabolic requirementand resistance totrauma.Skin grafts go through a unique process of healingin the host site. The first phase, which lasts 24 hours, is anischemic stage (called "plasmatic imbibition"), followed byan edematous stage in which the graft gains up to $40 \%$ in weight, and finally revascularization of the graft ("inosculation"), which becomes apparent within 48-72 hours aftergrafting. The blood supply to the graft comes from recipientbed ("bridging phenomenon") [6].

Because the eyelid is a layered structure, appropriate layered reconstruction is essential, with the goal towards restoring periocular function and minimizing any postsurgical complications [9].

The skin grafts can be classified according to their thickness. The most frequently used graft is the WolfeKrause graft $(0.80-1.00 \mathrm{~mm})$, taken from the skin with a scalpel. Other grafts are the thin-skin grafts, such as the Ollier-Thiersh graft $(0.20-0.35 \mathrm{~mm})$, and the middle-thickness grafts such as the Blair-Brown $(0.40-0.60 \mathrm{~mm})$ or Padgett $(0.60-0.80 \mathrm{~mm})$ grafts. Both thin-skin and middle-thickness grafts can only be taken with the use of a dermatome [3]. When used in periocular reconstruction they are usually harvested from several possible donor sites (upper lid, preauricular, retroauricular, neck, clavicular and supraclavicular, and inner brachial area) yielding different graft thicknesses accordingly [6].

The preauricular region is donor site of choice forsmaller defects on the upper two-thirds of the nose. The preauricular skin is a better color match compared with postauricular or supraclavicular skin. Harvesting the graft is much easier and better tolerated in a mildly sedated patient [8]. Bell finds the skin is in fact superior in quality to the postauricular graft. The donor site scar is minimal, because the typical person requiring a graft of this sort usually has a significant excess of skin on the cheek. The donor site morbidity is also much reduced. With the traditional postauricular skin graft, the patient's glasses often irritate the incision line. The largest area her taken to date measures $55 \mathrm{~mm} \times 25 \mathrm{~mm}$. Also, she found that the time required to perform this procedure is about one-half of that required to harvest postauricular [10]. 
Success of skin transplantation depends on graft revascularization. The blood supply to the graft comes from recipient bed. Therefore, important conditions for graft revascularization are rich vascular supply of recipient bed and very close contact between graft and recipient surface [1].

The early complications are mainly bleeding with hematoma formation beneath the graft, infection, or seroma formation. These complications may prevent graft adherence to the underlying wound bed, prolong the ischemic phase, compromise the graft's vascular supply, and result in graft failure [6].

Other possible reasons for graft failure are, infection, or graft movement. In the relevant literature, the most common early postoperative complication after skin transplantation is hematoma formation [1]. To prevent it, we made multiples stab incisions on the graft to create pathways for blood drainage.

The long term complications are mainly cosmetic orfunctional and result from color and texture mismatch, hyper- or hypopigmentation, graft hypertrophy, and graftcontraction [6].Usually the color of the graft is mixed, with dark and light spots and with time (after a week) it appears vital, light pink in color. If there are signs of ischemia after the first week, we can wait for 3 to 6 weeks, because survival rate is better than expected. A black graft signifies partial or total graft failure and necrosis. Risk for necrosis increased in cases with very thick graft with remaining subcutaneous fat tissue [1]. Graft contraction is secondary to centripetal movement of the unapposed elastic fibres, resulting in variable degrees ofshrinkage. The factors influencing shrinkage are mainly elasticity of the donor site and graft thickness. Graft contraction is believed to be more prominent as the thickness of the graft decreases, but it is generally thought that FTSG contract minimally in humans [6].

Graft hypertrophy was most common in medial canthal defect reconstruction compared with other periocular sites $[3,6]$. The exact mechanism for graft hypertrophy is not fully understood, and it probably represents aberration in the process of wound healing, which includes cell proliferation, inflammation, and increased synthesis of cytokines and extracellular matrix proteins [6]. There are different treatment approaches that include observation, pressure garments, massage and silicone gel sheets and intralesional injection of steroids $[1,6]$. The most common agents used are triamcinolone acetonide and triamcinolone diacetate which may be combined withpulsed dye lasers. Other possible treatment modalities are dermabrasion (such as aluminium oxidecrystals, acids, liquid nitrogen, and others) or laser CO2 resurfacing which may also improve texture and color abnormalities [6].

It is well known that all grafts contract, once immediately after excision from donor site andagain after revascularization. Primary shrinking is due to contraction of dermal elastic fibers, secondaryshrinking is result of myofibroblast activity.

In cases with FTSG primary shrinking is moreprominent than secondary. Contraction canbe overcome by massage with a steroid ointment for one month after surgery $[1]$.

Reconstruction of medial canthal after large tumourexcision is possible to perform with different surgical procedures. The surgical procedure must be individualized for each patient. A full- thickness excision of tumor is necessary. In our patient we prefer to use FTSG for reconstruction of anterior lamella of the eyelid, because this technique allows us to achieve recovery of the eyelid without any facial scars. In the present case, the preauricular area was the donor site. We prefer to use preauricular donor skin because the harvesting the graft is much easier and better tolerated in a mildly sedated patient, the donor site scar is minimal and the time required to perform this procedure is short.

Success of a skin graft attach depends on certain conditions: Avoid bleeding with formation of hematoma by moderate use of cautery. To prevent it, we made multiples stab incisions on the graft to create ways for blood drainage and a bolster placed over graft to push the skin against the recipient bed for 4 days, along ice compresses. Excess skin graft was trimmed. Normal lid position and functions are very important for eye protection and eye function. Aesthetic result after surgery is important not only for the patient, but also for the surgeon [1].

Medial canthal region reconstruction should be performed with preauricular FTSG considering color and tissue match and is useful alternative technique for the reconstruction of small defects. It can be performedunder local anesthesia obtaining satisfactory results cosmetically and functionally. The donor site scar is minimal. A simple surgical technique and 
acceptable donor site morbity are further advantages of this preauricular FTSG. Preauricular skin as a FTSG may provide a similar excellent tissue match in select cases.

\section{Consent}

The examination of the patient was conducted according to the Declaration of Helsinki principles written informed consent was obtained from the patient for publication of this article and any accompanying image.

\section{REFERENCES}

1. Zlatarora ZI, Nenkova BN, Softova EB. Eyelid reconstruction with full thickness skin grafts after carcinoma excision. Folia Med (Plovdiv). 2016.1;58:42-7.

2. Rahmi D, Mehmet B, Ceyda B, Sibel O. Management of the large upper eyelid defects with Cutler-Beard Flap.J Ophthalmol. 2014;2014:424567.

3. Bertelmann E, Rieck P, Guthoff R. Medial canthal reconstruction by a modified glabellar flap. Ophthalmologica. 2006;220:368-71.

4. Guido A, Actis GR. Reconstruction of the upper eyelid with flaps and free grafts after excision of basal cell carcinoma. Case Rep Ophthalmol. 2001;2:347-53.

5. Rathore DS, Chickadasarahilli S, Crossman R, Mehta P, Ahluwalia HS. Full thickness skin grafts in periocular reconstruction: long-term outcomes. Ophthal Plast Reconst Surg. 2014;30:517-20.

6. Leibovitch I, Huilgol SC, Hsuan JD, Selva D. Incidence of host site complications in periocular full thickness skin grafts. $\mathrm{Br}$ JOphthalmol.2005;89:219-22.

7. Wang YC, Dai HY, Xing X, Lv C, Zhu J, Xue CY. Pedicled lower lid-sharing flap for full-thickness reconstruction of the upper eyelid. Eye.2014;28:1292-6.

8. Weathers WM, Bhadkamkar M, Wolfswinkel EM, Thornton JF. Full-thickness skin grafting in nasal reconstruction Semin Plast Surg. 2013;27:90-5.

9. Hayano SM, Whipple KM, Korn BS, Kikkawa DO. Principles of periocular reconstruction following excision of cutaneous malignancy.J Skin Cancer. 2012;2012:438502.

10. Bell MS. Past the postauricular graft. Can J Plast Surg. 2008;16:95-6.

Copyright by Rafael Corredor-Osorio. This is an open-access article distributed under the terms of the Creative Commons Attribution License, which permits unrestricted use, distribution, and reproduction in any medium, provided the original author and source are credited.

Source of Support: Nil, Conflict of Interest: None declared. 